SCIREA Journal of Health

http://www.scirea.org/journal/PMH

September 28, 2021

Volume 5, Issue 5, October 2021

\title{
Applying the Theory of Planned Behavior to childbirth in Cross River State, Nigeria: A qualitative cross-sectional study.
}

\section{GinaMarie Piane ${ }^{1}$, Precious Chidozie Azubuike, ${ }^{2 *}$}

${ }^{1}$ Department of Community Health, College of Professional Studies, National University, San Diego, California.

${ }^{2}$ Department of Public Health, College of Medical Sciences, University of Calabar, Calabar, Nigeria.

\section{"Corresponding author}

Precious Chidozie Azubuike

Department of Public Health, College of Medical Sciences, University of Calabar, Calabar, Nigeria.

azubuikepreciousc@gmail.com

\begin{abstract}
Background: The Maternal Mortality Ratio in Nigeria remains the highest in Africa and second highest in the world. Best practices in reducing maternal deaths are to provide all women emergency obstetric care by trained attendants in well-equipped facilities.

Method: This research applies the Theory of Planned Behavioral to the behavior of delivering in hospitals in Nigeria. Qualitative responses from stratified random focus groups and key informant interviews in Cross River State, Nigeria conducted in December 2016,
\end{abstract}


were analyzed. The choice to deliver in a hospital can be explained and predicted by applying the Theory of Planned Behavior.

Results: The research sample was composed of 100 participants in 12 focus group discussions and 26 key informants. The participants expressed beliefs that negatively influence the choice of delivering sin hospitals. Fear of hospitals, Cesarean section, cost and spiritual attacks were common.

Conclusion: The application of the Theory of Planned Behavior to hospital delivery in Cross River State, Nigeria gives a clear direction to efforts to change patterns of behavior and to encourage more Nigerian women to deliver in the hospital. Public health educators need to address the deeply held beliefs regarding the safety of delivering in the hospital, the legitimate reasons for Cesarean section, and patients' rights to respectful treatment.

Keywords: Maternal Mortality, Theory of Planned Behavior, Nigeria, Qualitative Research methods

\section{Introduction}

Globally, maternal mortality has reduced remarkably by about $45 \%$ annually since 1990 as the estimated number of deaths during childbirth was reported to be 289,000 in $2013 .{ }^{1}$ Although this decline seems to progress, Sub-Saharan Africa recorded the largest share of maternal mortality in 2013, with 179,000 maternal deaths in the region. ${ }^{2}$

Despite efforts made by governments and international organizations towards improving access to skilled attendants during childbirth and to enhance emergency obstetric care as vital strategies to reduce the burden of maternal and neonatal mortalities, the use of skilled attendants during delivery has remained poor in developing countries. ${ }^{3}$

Nigeria contributes largely to the burden of maternal mortality in Sub-Saharan Africa, with 145 Nigerian women dying in childbirth every day; and one woman every ten minutes. ${ }^{4}$ One in thirteen Nigerian women will die in childbirth unless dramatic changes are made. Only one-third of births in Nigeria occur in a health facility. Less than one-quarter of Nigerian women receive post-natal care which includes monitoring and treating complications for 2 days after the delivery. ${ }^{5}$ 
The Theory of Planned Behavior (TBP) ${ }^{6}$ can be applied to explain and predict the behavior of delivering in a hospital. The most predictive antecedent to behavior is the behavioral intention which is formed by a positive attitude toward the behavior, a subjective norm that the behavior is expected, and a sense of control regarding the behavior. The TBP as shown in Figure 1 posits that an individual will consider performing a behavior when he or she evaluates it as beneficial, believing that others think it is important they perform such behaviors and assessing the behavior to be largely within their control. ${ }^{7}$ These salient beliefs are modified by the subjective evaluation of the beliefs, motivation to comply with community norms, and actual control regarding the behavior. The application of this model gives direction to efforts to change patterns of behavior and to encourage more Nigerian women to deliver within the safety net of emergency obstetric care. The study aimed to determine the utility of the theory in motivating Nigerian women to deliver in hospitals. 
Figure 1. Theory of Planned Behavior Applied to hospital delivery in Nigeria

\section{Behavioral Beliefs}

- Will be forced to have Cesarean Section after 2-3 hours of labor

- More likely to die in hospital

- Prophesy can determine outcome

\section{Evaluation}

- Cesarean Section is evil, wrong, the work of the devil

- Cesarean Section will reduce the total number of children

- Don't want to be first in family to have Cesarean Section

- Medical staff in hospital are harsh

\section{Normative Beliefs}

- Women have delivered for millennia at home

- Mother delivered at home

- Husband wants delivery in hospital

- Husband doesn't want to pay

- Need male children to pass on family name

\section{Motivation to Comply}

- Wife should submit to husband's will

- Teens do not yet have self-efficacy to resist

- Pressure on male to have many children

\section{Control Beliefs}

- TBA is cheaper than hospital

- Hospital will not allow placenta home for burial

- Hospital will not allow husband in delivery room

- Low self-efficacy to insist on respectful treatment

\section{Perceived Behavioral Control}

- Women have very little control over their healthcare

- Prophesy of death in hospital

\section{Actual Behavioral Control}

- Money is a barrier

- Hospital policies create barriers

- Free care is not really free

- No ambulances 


\section{Materials and Methods}

This qualitative study, conducted in December 2016 in Cross River State, Nigeria, employed a multi-stage sampling technique to select participants. First, a simple random sampling technique was employed to select local government areas (LGA) and one ward from each. Within each ward, key informants and focus group participants were selected to provide a variety of informed opinions. The participants in the focus groups included women of childbearing age, men, traditional birth attendants, and nurses. Pregnant women and persons under the age of 18 were excluded. Key informants included government officials, health professionals, traditional birth attendants, and leaders of faith communities.

The key informant interview and focus group questions were developed to enhance the information gathered in the literature review and to solicit opinions regarding the challenges and opportunities to decrease maternal deaths. The interview guides were formulated to obtain direct measures of attitude toward the behavior, perceived norms, and perceived behavioral control. The questions were tailored for the particular focus group. Participants were also asked to complete a brief survey of demographic data and their experience with maternal deaths in their families, friends, or community.

For the key informant interviews: Each key informant was asked to participate in a 30-minute in-person personal interview by appointment. The focus groups lasted 60 minutes each. Each participant was asked for written and verbal informed consent to participate in the study and for the interview to be recorded.

\section{Data analysis}

All audio recordings from both the key informant interviews and focus group discussions were transcribed verbatim and analyzed by themes that reflect the constructs of the TPB. Atlas TI- 8 software was used in the analysis of the transcripts to create codes, link them to quotes, and determine their frequencies.

\section{Results}

Table 1 (one) compares the research sample with the nation and state and also compares the key informants to the focus group participants. Women were deliberately overrepresented in 
the focus groups. The focus groups were restricted to those over the age of 18 years; therefore our sample is slightly older and has higher educational attainment than the general population. As expected, the key informants were older and more highly educated than the focus groups. ${ }^{8}$

Table 1. Comparison of Research Sample to Population of Cross River State and Nigeria

\begin{tabular}{|c|c|c|c|c|c|}
\hline & Nigeria & $\begin{array}{l}\text { Cross River } \\
\text { State }\end{array}$ & $\begin{array}{l}\text { Research } \\
\text { Sample }\end{array}$ & $\begin{array}{c}\text { Key } \\
\text { Informants }\end{array}$ & $\begin{array}{c}\text { Focus } \\
\text { Group } \\
\text { Discussion }\end{array}$ \\
\hline Population & 177 million & $2,892,988$ & 126 & 26 & 100 \\
\hline Male & $\begin{array}{c}92 \text { million } \\
(52 \%)\end{array}$ & $\begin{array}{c}1,471,967 \\
(51 \%)\end{array}$ & $34(27 \%)$ & $12(46 \%)$ & $22(22 \%)$ \\
\hline Female & $\begin{array}{l}85 \text { million } \\
(48 \%)\end{array}$ & $\begin{array}{c}1,421,021 \\
(49 \%)\end{array}$ & $92(73 \%)$ & $14(54 \%)$ & $78(78 \%)$ \\
\hline $\begin{array}{c}\text { Average } \\
\text { Educational } \\
\text { Status }\end{array}$ & 1.5 & 1.36 & 2.3 & 2.9 & 2.2 \\
\hline Literacy Rate & $60 \%$ & $74 \%$ & & & \\
\hline Average Age & 18.3 years & & 35 years & 47 years & 26 years \\
\hline MMR & $\begin{array}{c}630 \text { per } \\
100,000 \\
\text { births }\end{array}$ & $\begin{array}{c}545 \text { per } \\
100,000 \text { births }\end{array}$ & & & \\
\hline $\begin{array}{l}\text { Average Family } \\
\text { Size }\end{array}$ & 5.13 children & $\begin{array}{c}5.9 \\
\text { Children }\end{array}$ & 3.65 children & 4.73 children & 2.71 children \\
\hline Poverty Rate & $63 \%$ & $67 \%$ & & & \\
\hline Ethnic Groups & $\begin{array}{l}250 \text { Ethnic } \\
\text { Groups }\end{array}$ & $\begin{array}{l}26 \\
\text { Ethnic Groups }\end{array}$ & $\begin{array}{c}6 \\
\text { Ethnic Groups }\end{array}$ & $\begin{array}{c}6 \\
\text { Ethnic Groups }\end{array}$ & $\begin{array}{c}6 \\
\text { Ethnic Groups }\end{array}$ \\
\hline
\end{tabular}

The participants expressed deeply held behavioral beliefs regarding hospital delivery. The responses indicate a dissonance between beliefs and desire to deliver in hospitals. Most of the beliefs negatively influence the choice of delivering in hospital while the vast majority of respondents expressed that they would prefer to deliver in hospital if that choice was available to them. 
Some expressed beliefs that women can safely give birth without help. "Some feel they are strong enough to take care of themselves, which is why they don't want to come to the hospital. They say that after delivery, they can cut and clean themselves" (Mbube Woman). Others believe that the Traditional Birth Attendants care more about them than the hospital staff". "I delivered all my three children at home. I like TBAs because they will help me deliver the baby while the hospital does not really care (Woman in Duke Town)"

The majority of opinions echoed the belief that delivery is safer in the hospital, however, money is a barrier. "I will go to the hospital and get all the advice I need from there (Akpabuyo Woman)." "The most important place is that they should go to the hospital but some don't go because of the finances involved! (Man in Yakurr)."

A common theme among the respondents was that women fear going to the hospital because they believe that the hospital staff will coerce them into having a Cesarean section (CS). "Some hospitals are so greedy; they will not even allow the person to labor so that they will collect huge amount of money (Woman in Bekwarra)."

The fear has evolved from a supernatural belief that CS is due to a spiritual attack or is ungodly. "Some people believe that anyone who has undergone CS has a spiritual hand behind it, it is not normal and it is something that is forbidden (Woman in Akpabuyo)." Many hold dissonant beliefs that include both spiritual reasons and medical reasons for CS. "Yes, people talk of it because it is believed that God didn't design any woman to deliver through CS. I believe the only way to save both the baby and the mother is through CS. (Woman in Etung).”

"You cannot completely rule out that a lot of persons see it as wrong, a lot of persons detest it because they fear that if a woman is operated upon for a number of times, she cannot have more children like she will want to. We live in a community where some persons desire up to five or ten children. (Man in Yakurr).",

"Once you mention CS here, it is as though you have sentenced the person to death. Maybe she didn't come early and it resulted in uterine rupture...they say that after a CS, the person may not conceive again, or someone they know died as a result of CS may be in anesthesia and because of that, they run away from surgery or feel reluctant in doing it (Medical Doctor)."

Another theme that arose in the interviews was that maternal death can be attributed to spiritual attacks and that medical staff are helpless in those cases. "Because the way your 
attack will be; nurses cannot help you. You need serious prayer with a man of God who has spiritual eyes (Woman in Etong).' The spiritual attacks were often described as originating with a family member or a witch. "Some pastors, when they see that someone wants you dead, they ask you to stay in the church and they pray till the baby comes out (Woman in Yakurr)." "Before she died, when pregnant, her husband won't allow her to go to the hospital and he believed that his prayers would work. He refused to take her to the hospital until the woman and baby died (Woman in Bekwarra)."

The most common complaint and belief expressed was that the nurses in hospitals treat women so harshly that the women do not want to deliver in the hospital. "Because when she goes to the hospital, the woman finds out that she is treated harshly. She might even decide to change hospitals or not to go to any hospital with the mindset that they are all the same (Man in Akpabuyo). "Some defended nurses who behave harshly by stating that women can be stubborn, however, most disagreed with harsh treatment stating that pregnant women need to be pampered. "Yes, I know too well that so many nurses are so harsh; I believe that if a nurse is harsh to you and your husband is there, he should talk to her and ask her to attend to you kindly. (Village Councilor)."Women described nurses who shout and even hit them during delivery. "It is because of the attitudes of the health workers most times that keep them away from the hospital. (Woman in Akpabuyo)"

The Nigerian people that we interviewed were not of one mind regarding beliefs about hospital delivery, many held conventional beliefs that modern medicine can help them to survive. "I will go to the hospital because if I can't push the baby, the doctors and nurses know what to do. But if I give birth at home, when there is a complication, death will come (Woman in Etung). "Most participants described reasons for delivering in the hospital that is consistent with orthodox medicine. "I think it is good for women to go to the hospital during pregnancy and delivery because, at the TBA, the equipment used are unhygienic. But are highly hygienic in the hospital. (Woman in Akpabuyo)."

Many expressed disagreements with their neighbors regarding their beliefs, labeling them as ignorant. "I think it is ignorance, they don't know the importance of going to the hospital. (Man in Akpabuyo). 'Nigeria is a highly religious nation so it was surprising to hear from non-believers. "I don't believe in Spirituality. I believe it is ignorance. (Man in Akpabuyo). "Some pastors warn against orthodox medicine and modern drugs. "They believe that once you go to the church, you are not supposed to take any drugs that God will help you 
deliver. For me, it is a bad idea. If you must go to the church, take the drugs, go there and deliver, the drugs will help you (Village Councilor)."

Normative beliefs reflect the perception of the behavior of others in the community. There is often a strong motivation to comply with the expectations of others. One way that the community sets expected behavior is to associate the behavior with religion. "Going back to the Biblical aspect, Our Lord Jesus was not born in the hospital (Man in Yakurr). ”Another is to consider the behavior, in this case, delivery at home, to be normal and accepted. "Some of them will try it at home and if they see that there is no way out, they come here (PHC Director). "Attributing positive outcomes to delivery at home can inform the acceptance of the behavior. "Some women deliver at home and they do it successfully when the finance is not there (Woman in Yakurr). "In addition, excusing the behavior also contributes to normative beliefs. "Sometimes, finance makes them go to cheaper places. Some go to TBAs and maternity since the government does not help them pay (Man in Yakurr)."

Most of the control beliefs voiced by the respondents indicated an external locus of control, either God or other spirits are in control, or powerful others at the hospital control their behavior. "Some prefer going to the church to deliver because of their belief in God. Especially when they suspect a witch in their family, some believe that someone in their family can harm their babies (Woman in Akpabuyo)."

One of the behaviors that is important to the participants and out of their control if they deliver in hospital is the ritual burial of the placenta. "Truly, placenta is important. The person who buries it matters because some people can manipulate it and can bless or curse the child. The placenta should be buried by the right hand that is, either her husband or someone she trusts at that moment (man in Yakurr). "Burying the placenta is said to affect the child's future. "We believe that if it is not buried, the naval will not heal. (Man in Akpabuyo)."

The most common barrier to delivery in the hospital was the cost of care. Most respondents desired to deliver in the hospital but couldn't afford the care. "There is no money to take her to the hospital and that is why she stays home because the doctor demands for money and they may not have the money to pay (Woman in Etung). "Almost all of the participants in the interviews and focus groups believed that the government should provide maternity care free of charge. "If the government provides, it will be good. If government will step in, it will be available and affordable and people will go to the hospitals (Man in Yakurr)." 


\section{Discussion}

The desire of any individual to perform any behavior is informed by the individual's attitude towards the behavior, the perceived subjective norms, and how much control he or she feels they are in, over the behavior. ${ }^{8}$ The behavior of interest in this study was hospital delivery. The TPB holds that this can be influenced by the woman's behavior towards birth in a health facility, the norms she has subjectively about hospital delivery, and her perceived control on delivering in a hospital. ${ }^{9}$

The study revealed inconsistencies between beliefs and the willingness towards hospital delivery in the study area. A possible explanation of the dissonance between beliefs and desire to deliver in hospital is that when given little choice, people may rationalize and justify their behavior. Women would prefer to deliver in the safety of a hospital, however; the barriers are too difficult to overcome. Some of these barriers as reported in other studies may include low-risk perception towards pregnancy and childbirth. ${ }^{10}$ When people perceive pregnancy and childbirth as a normal process and do not recognize the possible associated risks, it may lower their intention to use a health facility for childbirth. ${ }^{10}$ Subsequently, they defend their decision to deliver at home. The community may be diminishing the importance of their beliefs to create more comfort with the dissonance between knowing that hospital delivery is safer and their behavior of delivering at home.

The application of the Theory of Planned Behavior to hospital delivery in Cross River State, Nigeria gives a clear direction to efforts to change patterns of behavior and to encourage more Nigerian women to deliver in the hospital. First, it is necessary to provide emergency obstetric care for all women in Nigeria. The government must provide free or affordable quality care and regulate the treatment of women in labor and during delivery. Patient advocacy groups should develop a patient's 'bill of rights' and empower women and their families to demand respectful maternity care. Women who are treated well and experience positive outcomes will consequently advocate for hospital delivery among their families, friends and community.

Health promotion programs and interventions need to address the beliefs regarding the maternal mortality ratio in Nigeria and the perception that women die more frequently in hospitals than at home. If all women were delivered in hospital, the risk would be reduced and there would be no disparity between hospital and home deliveries. 
Another key element that should be included in health promotion is to educate the community regarding the valid reasons for Cesarean section (CS). According to the World Health Organization, ${ }^{1}$ only $1.8 \%$ of births in Nigeria are delivered by Cesarean section, which is significantly below the recommended rate of $10 \%-15 \%$. An increase in the rate of CS in Nigeria would decrease maternal mortality if the procedures are performed by adequately trained surgeons inadequately equipped facilities.

Finally, health promoters in Nigeria need to educate community leaders regarding the dangers of delivery at home and in churches. Clear, factual educational materials could be developed tailored to the needs of each village. The public health community can work with the leaders to form community coalitions to combat the cultural beliefs that influence women to endanger their lives by not delivering in a hospital.

The current research is limited to a select sample of key informants and focus group participants in Cross River State, Nigeria, and may not fully represent the various cultural groups in Nigeria especially the largely Muslim groups to the north. The study participants may also not represent the true diversity of opinions. Since the focus groups were conducted in Primary Health Centres (PHC), community members who do not frequent the PHCs and those who deliver at home or in church with a TBA may be underrepresented.

In order to reduce maternal mortality in Nigeria, women need to be delivered in hospitals. The choice to deliver in a hospital can be explained and predicted by applying the Theory of Planned Behavior. There are considerable differences among Nigerians regarding beliefs regarding the supernatural and medical aspects of surviving childbirth and place of delivery. These beliefs need to be addressed if women are expected to choose hospital delivery. Commitment is needed among global public health leaders to identify best practices in reducing maternal mortality and to implement programs with strong theoretical underpinnings.

\section{Acknowledgements}

Drs. Ndep and Ejemot-Nwadiaro, along with Dr. Piane developed the research protocol, the focus group guides, and interview questions, and recruited participants. 


\section{Funding}

This work was supported by a J. William Fulbright US Scholar grant.

\section{Ethical approval}

This research was granted ethical clearance from the Cross River State Ministry of Health, the National University and the University of Calabar Institutional Review Boards.

\section{Authors' contributions}

Dr. GinaMarie Piane conceptualized the research in her proposal for a US Fulbright Scholar grant, conducted the discussions and interviews, coded the transcripts and applied the themes to produce this manuscript.

Precious Chidozie Azubuike performed the recordings and transcriptions and was involved in planning. He processed the qualitative data, participated in the analysis, contributed to the design and implementation of the research, to the analysis of the results, and to the writing of the manuscript.

\section{References}

[1] World Health Organization. "WHO, UNICEF, UNFPA, World Bank Group, and United Nations Population Division Trends in Maternal Mortality: 1990 to 2015 Geneva. http://apps.who.int/iris/bitstream/10665/112682/2/9789241507226 eng.pdf?ua=1. Accessed 23 February 2021.

[2] United Nations. The Millenium Development Goals Report, United Nations, 2014, http://www.un.org/millenniumgoals/reports.shtml. Accessed 23 February 2021.

[3] Netemeyer RM, RynVan I, Ajzen P. "The theory of planned behavior," Organizational Behavior and Human Decision Processes. 1991;50(12):179-211 doi: http://linkinghub.elsevier.com/retrieve/pii/T

[4] United States Central Intelligence Agency. 2016 World Fact Book. https://www.cia.gov/library/publications/the-world-factbook/. Accessed 29 July 2016. 
[5] Lanre-Abass B.A. Poverty and maternal mortality in Nigeria: Towards a more viable ethics of modern medical practice. International Journal for Equity in Health. 2008;7:1125.

[6] Ajzen I. Theory of Planned Behavior. http://people.umass.edu/aizen/tpb.diag.html. Accessed 26 May 2017.

[7] Gibbons L, Belizán JM, Lauer JA, Betrán AP, Merialdi M, Althabe F. "The Global Numbers and Costs of Additionally Needed and Unnecessary Caesarean Sections Performed per Year: Overuse as a Barrier to Universal Coverage”. World Health Report Background Paper, No 30.

[8] Tulsi Chanrai Foundation. Cross River State: Cross River State Community Health Department Health Primary Care Program. http://www.tcfnigeria.org/index.php?option $=$ com_content\&view $=$ article\&id $=126 \&$ Itemi $\underline{\mathrm{d}=548}$. Accessed 19 August 2016.

[9] Moshi FV, Kibusi SM, Fabian F. Using the theory of planned behavior to explain birth in health facility intention among expecting couples in a rural setting Rukwa Tanzania: a cross-sectional survey. Reproductive Health. 2020;17;2-5. doi: https://doi.org/10.1186/s12978-020-0851-1

[10] Naghavi M, Wang H, Lozano R, Davis A, Liang X, Zhou M, et al. Global, regional, and national age-sex specific all-cause and cause-specific mortality for 240 causes of death, 1990-2013: a systematic analysis for the global burden of disease study 2013. Lancet. 2015;385(9963):117-71. doi: https://doi.org/10.1016/S0140-6736(14)61682-2.

[11] Moshi F, Nyamhanga T. Understanding the preference for homebirth; an exploration of key barriers to facility delivery in rural Tanzania. Reprod Health. 2017;14(1):132 doi: http://reproductive-health-journal.biomedcentral.com/articles/10.1186/s12978-017-0397z. 